\title{
Perceptions, Practices and Health Hazards, of Agricultural Workers from Rural Central India with Regard to Pesticide Use - A Cross Sectional Study
}

\author{
Rahul Thakur ${ }^{1}$, Prashil Jumade ${ }^{2}$, Rutuj Waghmare ${ }^{3}$, Shobha Joshi ${ }^{4}$, Abhishek Joshi ${ }^{5}$ \\ 1, 2, 3, 4, 5 Department of Community Medicine, Datta Meghe Institute of Medical Sciences, \\ Sawangi (M), Wardha, Maharashtra, India.
}

\section{ABSTRACT}

\section{BACKGROUND}

Agriculture is a major field of India's economy. Agriculture is the primary livelihood for over $58 \%$ of rural households. 500,000 - 1,000,000 people globally suffer from health consequences as a result of pesticide poisoning every year, according to the World Health Organisation. In countries such as India, pesticide poisoning is a major health problem and is more prevalent. The purpose of this study is to find out the perceptions \& practices followed by agricultural workers from study area with regard to use of pesticides.

\section{METHODS}

This was a community-based cross-sectional study. 380 Agricultural workers across three villages participated in the study and all agricultural workers who were $>18$ years of age and were handling pesticides for $>1$ year were included in study. Simple random sampling method was used, and data was collected using interview schedule.

\section{RESULTS}

$35 \%$ of the study participants were educated up to middle school and $49.21 \%$ were in age group of 38 - 57 years. $63.84 \%$ participants thought pesticides are harmful while only $25 \%$ knew about route of entry of pesticides into the human body. $52.1 \%$ of the study participants had headache as a morbidity feature followed by skin irritation in $44.2 \%$. The association between perception of harmful effects of pesticides and gender, age, education \& socio-economic status was found to be statistically significant ( $\mathrm{p}=0.012, \mathrm{p}=0.004, \mathrm{p}<0.001, \mathrm{p}<0.001$ respectively).

\section{CONCLUSIONS}

About $2 / 3^{\text {rd }}$ of study participants thought that pesticides are injurious to health \& environment. While only $1 / 4^{\text {th }}$ participants knew about of route of entry of pesticides into the body. Headache followed by skin irritation were the commonest reported toxic effects of pesticide use. Association between perception of harmful effects of pesticides and socio-demographic profile was found to be statistically significant.

\section{KEY WORDS}

Pesticides, Agricultural Workers, Health Hazards, Rural Central India
Corresponding Author: Dr. Abhishek Joshi, Associate Professor, Department of Community Medicine, Datta Meghe Institute of Medical Sciences, Sawangi (M), Wardha, Maharashtra, India. E-mail: abhishekunjoshi@yahoo.com

DOI: $10.14260 /$ jemds/2020/774

How to Cite This Article:

Thakur R, Jumade P, Waghmare R, et al. Perceptions, practices and health hazards, of agricultural workers from rural central India with regard to pesticide use - a cross sectional study. J Evolution Med Dent Sci 2020;9(47):3528-3532, DOI: $10.14260 /$ jemds/2020/774

Submission 20-07-2020,

Peer Review 02-10-2020,

Acceptance 08-10-2020,

Published 23-11-2020.

Copyright (C) 2020 Rahul Thakur et al. This is an open access article distributed under Creative Commons Attribution License [Attribution 4.0 International (CC BY 4.0)] 


\section{BACKGROUND}

Agriculture is a major field of India's economy. Agriculture is the primary source of income for over $58 \%$ of rural households. ${ }^{1,2} 500,000-1,000,000$ people globally suffer from health consequences as a result of pesticide poisoning every year, according to the World Health Organisation. ${ }^{3}$

The term pesticide refers to any chemical substance or mixture of substances intended for preventing, destroying, repelling, or mitigating any pest." FIFRA's definition of pesticides includes plant growth regulators, defoliators, and desiccants. ${ }^{4}$ Pesticides production is monitored by stringent regulatory mechanism that ensure minimal impact on human and environment health; serious health risks as a result of occupational exposures, as well as residues in food and drinking water, have been raised.

A wide variety of pesticides are widely used in citrus, vegetable and other crop areas in order to enhance agricultural production, including organochloride, biophosphorus, carbamate and pyrethroid insecticides, fungicides and herbicides. ${ }^{5}$

Pesticide poisoning is a major global health problem and is more prevalent in countries like India. It has a well-established adverse effect on humans in the form of acute and chronic toxicity due to pesticide. Chronic exposure has, moreover, been linked to the other health problems described in several publications, for example, polyneuropathy, dermatitis, compartmental changes, and cancer. Accidental chronic toxicity due to failure to implement adequate preventive measures during spraying is known, but few studies in this regard have been conducted. Most of the insecticide exposure workers on the farm are illiterate, with insecticide absorption through the skin, breathing or oral tract, which can cause acute toxicity and are unaware of the necessary toxic effects and preventive measures. Long term exposure to sub-toxic doses leads to harmful effects on different systems, for example. Neurotoxicity, toxicity to neuro-endocrines, cancer, etc. ${ }^{6}$

The Occupational Safety and Health Administration (OSHA) reports that 243 agricultural workers every day experience a severe loss of working time injury. Five percent of the wounds are permanently affected. In 2010, the loss rate was 20 percent higher for agricultural workers than for all employees. This is a reasonable calculation because many other incidents are never recorded and many injuries are attributed to underreported family members. Many agricultural and ranch injuries could be prevented or reduced by the use of personal safeguards by farmers. ${ }^{7}$

Pesticides have caused deaths, and debilitation across India, either through self-poisoning, deliberate or accidental poisoning. Within the easy of reach of the depressed and stressed persons, pesticides have become a causal factor in the loss of numerous lives, of agricultural works, women, girls, boys, and children.

The purpose of this study was to find out the perceptions \& practices followed by agricultural workers from study area with regard to use of pesticides and to determine the morbidity pattern with regard to pesticide use.

\section{METHODS}

After obtaining approval from Institutional Ethical Committee a community-based cross-sectional study was carried out in three villages which were adopted by the institute for various community related activities. Study was conducted from July 2019 to Feb 2020. Written informed consent was obtained from each study participants before the start of interview.

\section{Sample Size and Sampling Method}

The sample size was calculated by using sample size formula.

$\mathrm{n}=\frac{\mathrm{X}^{2} \cdot \mathrm{N} \cdot \mathrm{P} \cdot(-\mathrm{P})}{\mathrm{C}^{2}(\mathrm{~N}-1)+\mathrm{X}^{2} \mathrm{P}(1-\mathrm{P})}$

Where,

Total population of all villages $=19539$ (censes 2011)

$\mathrm{X}^{2}=$ chi-square value for $1 \mathrm{df}$ at $5 \%$ level of significance $=3.84$

$\mathrm{P}=50 \%$ proportion $=0.50$

$\mathrm{C}=$ Confidence interval of one choice $(95 \% \mathrm{CI})=0.05$

$\mathrm{N}=\frac{3.84 \times 19539 \times 0.50 \times 0.50}{0.05^{2} \times 19539+3.84 \times 0.50 \times 0.50}$

$=376.59$

Hence, rounding up the sample size for the study was 380 . The study participants to be interviewed from each village was determined by using sample in proportion to population of each village. The list of eligible participants as per inclusion criteria was obtained from Gram panchayat office which was utilised as sampling frame and the estimated numbers from each village were achieved by using simple random sampling method.

\begin{tabular}{|cccc|}
\hline Sl. No. & Village Name & $\begin{array}{c}\text { Population } \\
\text { (Census 2011) }\end{array}$ & $\begin{array}{c}\text { Sample in Proportion to } \\
\text { Population }\end{array}$ \\
1 & Umari (Meghe) & 7916 & 154 \\
2 & Waigaon (Nipani) & 8154 & 159 \\
3 & Salod & 3469 & 67 \\
Total & & $\mathbf{1 9 5 3 9}$ & $\mathbf{3 8 0}$ \\
\hline \multicolumn{4}{|c|}{ Table 1. Distribution of Villages under Study } \\
\hline
\end{tabular}

\section{Study Participants}

Agricultural workers $>18$ years of age working in their own farm or other's farms for more than 1 year and who are using pesticides were included in the study. Agricultural workers who were not willing to take part in the study were excluded.

\section{Study Tool}

A pre-designed and semi-structured questionnaire was prepared, edited and modified and finalized as per inputs of piloting, the finalized tool was validated by the project guide and implemented for data collection using interview technique. Data collection was done by principal investigator to avoid inter-observer bias \& the final tool comprised of following components

- Socio-demographic profile of the agricultural workers included age, sex, education, total family income, mode of farming etc. 
- Perceptions \& practices regarding the use of pesticides.

- Health hazards reported by agricultural workers after using pesticides.

\section{Statistical Analysis}

Data collected was entered into Microsoft excel spreadsheet and data were analysed by using Epi Info statistical software. Percentage \& proportions were calculated for descriptive statistics and association was tested using chi square test.

\section{RESULTS}

\begin{tabular}{|c|c|c|c|}
\hline \multicolumn{2}{|c|}{ Characteristic } & $n=380$ & $\%$ \\
\hline \multirow{7}{*}{ Education } & Illiterate & 51 & 13.42 \\
\hline & Primary school & 119 & 31.31 \\
\hline & Middle school & 133 & 35 \\
\hline & High school & 51 & 13.42 \\
\hline & Higher secondary school & 19 & 5 \\
\hline & Graduate & 5 & 1.31 \\
\hline & Post Graduate & 2 & 0.52 \\
\hline \multirow{3}{*}{ Age } & $18-37$ & 113 & 29.74 \\
\hline & $38-57$ & 187 & 49.21 \\
\hline & $58>$ & 80 & 21.05 \\
\hline \multirow{3}{*}{ Type of Family } & Joint & 182 & 55.26 \\
\hline & Nuclear & 132 & 41.31 \\
\hline & Three generation & 13 & 3.42 \\
\hline \multirow{3}{*}{ Mode of farming } & Full time & 272 & 71.57 \\
\hline & Seasonal & 108 & 28.42 \\
\hline & Class - 1 & 12 & 3.15 \\
\hline \multirow{3}{*}{$\begin{array}{c}\text { Socioeconomic status } \\
\text { (Modified BG Prasad scale ) }\end{array}$} & Class - 2 & 37 & 9.73 \\
\hline & Class - 3 & 162 & 42.63 \\
\hline & Class - 4 & 169 & 44.47 \\
\hline \multicolumn{4}{|c|}{ Table 2. Socio-Demographic Details } \\
\hline
\end{tabular}

The above table shows the socio-demographic details of the present study participants. About $35 \%$ of the study participants were educated up to middle school followed by $31.31 \%$ educated up to primary school.

While only 2 participants were educated up to postgraduate level. Maximum $49.21 \%$ study participants belonged to the age group of 38 to 57 years and $21.05 \%$ study participants were of age more than or equal to 58 years. When asked about the type of family, it was found that about 55.26 $\%$ were living in the joint family while, only $3.42 \%$ were living in three generation family. About $3 / 4^{\text {th }}$ of the study participants were having full time farming. When asked about socio-economic status, it was observed that about $44.47 \%$ study participants belonged to class 4 socio-economic status by Modified B.G. Prasad classification.

\begin{tabular}{|ccc|}
\hline Think Pesticides are Harmful & $\mathbf{n}$ & $\mathbf{\%}$ \\
Yes & 243 & 63.94 \\
No & 137 & 36.05 \\
Through Skin & & \\
Inhalation & 33 & 8.68 \\
Oral & 39 & 10.26 \\
Eye Contact & 9 & 2.36 \\
All of the Above & 8 & 2.10 \\
Don't Know & 5 & 1.31 \\
Read, Understand and Follow Label on Pesticides & 75.26 \\
Always & 170 & 44.73 \\
Never & 186 & 48.94 \\
Some Time & 24 & 6.31 \\
& Hand Washing Practices & \\
Wash Hands Using Soap & 162 & 42.63 \\
Wash Hands Using Plain Water & 214 & 56.31 \\
Don't Wash & 4 & 1.05 \\
\hline Table 3. Knowledge \& Perception Regarding Pesticide Use \\
\hline
\end{tabular}

From the above table we came to know that about $63.94 \%$ study participants were having knowledge that pesticides are harmful. But, about $75.26 \%$ were not having knowledge regarding the way of entry of pesticide in the human body. While, $10.26 \%$ study participants told that pesticide enter body through inhalation and about $8.68 \%$ study participants told that pesticides enter the body through skin. When asked about reading the instruction on the pesticide label, it was found that maximum $48.94 \%$ study participants never read the instruction. While, about $44.73 \%$ study participants always read the instruction and about $6.31 \%$ study participants read it sometime. Also, it was found that maximum $56.31 \%$ study participants washed their hand with plain water after pesticide use and about $1.05 \%$ did not even wash their hands. While, about $42.63 \%$ study participants washed their hand with soap.

\begin{tabular}{|ccc|}
\hline Symptoms & $\mathbf{n}$ & $\mathbf{\%}$ \\
Headaches & 198 & 52.10 \\
Dizziness & 32 & 8.42 \\
Skin Irritation & 168 & 44.21 \\
Nausea & 139 & 36.57 \\
Itchy Eyes & 121 & 31.84 \\
Vomiting & 89 & 23.42 \\
Coughing & 105 & 27.63 \\
Shortness of Breath & 18 & 4.73 \\
Excessive Sweating & 27 & 7.10 \\
Fatigue & 123 & 32.36 \\
Stomach Ache & 11 & 2.89 \\
Blurred Vision & 105 & 27.63 \\
\hline Table 4. Toxic Effects of Pesticide Use \\
\hline \multicolumn{2}{|c}{} \\
\hline
\end{tabular}

When asked for the toxic effects from the pesticide use, maximum $52.1 \%$ study participants complained about having headache followed by $44.21 \%$ having skin irritation. About $36.57 \%$ study participants experienced nausea, $31.84 \%$ had itchy eyes \& $32.36 \%$ had fatigue. While, only $4.73 \%$ \& $2.89 \%$ study participants were having shortness of breath \& stomach ache respectively.

\begin{tabular}{|c|c|c|c|c|}
\hline & \multicolumn{3}{|c|}{$\begin{array}{l}\text { Think Pesticides are } \\
\text { Harmful }\end{array}$} & \multirow[t]{2}{*}{$\mathrm{X}^{2} \&$ P-Value } \\
\hline & & Yes & No & \\
\hline \multirow[b]{2}{*}{ Gender } & Male & $201(61 \%)$ & $12639 \%$ & \multirow{2}{*}{$\begin{array}{c}\text { Fisher Exact Test } \\
\text { applied } \\
\mathrm{p}=0.012^{*}\end{array}$} \\
\hline & Female & $42(79 \%)$ & $11(21 \%)$ & \\
\hline \multirow{4}{*}{ Age } & $18-37$ & $65(58 \%)$ & $48(42 \%)$ & \multirow{4}{*}{$\begin{aligned} \mathrm{X}^{2} & =11.124 \\
\mathrm{p} & =0.004^{*}\end{aligned}$} \\
\hline & $38-57$ & $123(66 \%)$ & $64(34 \%)$ & \\
\hline & $58>$ & $55(69 \%)$ & $25(31 \%)$ & \\
\hline & Illiterate & $6(12 \%)$ & $45(88 \%)$ & \\
\hline \multirow{3}{*}{ Education } & Primary, Middle, & $172(68 \%)$ & $80(32 \%)$ & \multirow{2}{*}{$\begin{aligned} \mathrm{X}^{2} & =22.853 \\
\mathrm{p} & <0.001\end{aligned}$} \\
\hline & $\begin{array}{l}\text { High \& Higher } \\
\text { Secondary School }\end{array}$ & $58(83 \%)$ & $12(17 \%)$ & \\
\hline & Graduate, Post Graduate & $7(100 \%)$ & $0(0 \%)$ & \multirow{5}{*}{$\begin{aligned} X^{2} & =66.733 \\
p & <0.001^{*}\end{aligned}$} \\
\hline \multirow{4}{*}{$\begin{array}{c}\text { Socio- } \\
\text { economic } \\
\text { Status }\end{array}$} & Class -1 & $9(75 \%)$ & $3(25 \%)$ & \\
\hline & Class - 2 & $32(86 \%)$ & $5(14 \%)$ & \\
\hline & Class - 3 & $99(61 \%)$ & $63(39 \%)$ & \\
\hline & Class - 4 & $103(61 \%)$ & $66(39 \%)$ & \\
\hline \multicolumn{5}{|c|}{$\begin{array}{l}\text { Table 5. Association between Socio-Demographic Details } \\
\text { \& Perception of Harmful Effects of Pesticide Use }\end{array}$} \\
\hline
\end{tabular}

Out of all males, about $61 \%$ \& out of all female study participants, about $79 \%$ thought pesticide were harmful for the human being. The association between gender \& thinking of pesticides being harmful was found to be statistically significant $(p$-value $=0.012)$. When compared with the age, it was found that of all age groups more than half of the study participant thought pesticide as harmful and the association between age group \& perception regarding harmfulness of the pesticide were found to be statistically significant $(\mathrm{p}$-value $=$ 
0.004). All the study participants educated up to graduation \& post-graduation thought that pesticide are harmful, while about $88 \%$ of those who are illiterate did not think pesticide as harmful. The association between education \& perception of study participants regarding harmfulness of pesticide were found to be statistically highly significant ( $p$-value $<0.001$ ). Thus, we can say that more the education of the person, better is the perception regarding the harmfulness of the pesticide. Also, out of all study participants belonging to class 1 about 75 $\%$ thought pesticides were harmful. While out of all study participants belonging to class $3 \& 4$ about $39 \%$ each did not think pesticide as harmful. The association between socioeconomic status \& perception of study participants regarding harmfulness of pesticide was found to be statistically highly significant ( $p$-value $<0.001$ ) indicating better the socioeconomic status better the perception regarding pesticide.

\section{DISCUSSION}

In the present study, 380 participants participated in the study out of which 327 were males and 53 were females with age group 18 - 27 year (6\%), 28 - 37 year (23.68\%), 38 - 47 year (29.73\%), 48 - 57 year (19.47\%), 58 - 67 year (15.78\%), 68 77 year $(4.21 \%)$, and 78 year or above $(1.05 \%)$. (Un-tabulated data)

Similar results was found in a study done by Ali Javed, et al which showed 15 - 30 years (54\%), 30 - 45 years (30\%) and 45 or above (14\%) age range in Karachi. 8

In the present study, $13.42 \%$ participant were illiterate, $86.58 \%$ participants were educated in which $31.31 \%$ educated up to primary school, middle school (35\%), high school (13.42\%), the higher secondary school (5\%), graduate (5\%), postgraduate $(0.52 \%)$.

In the current study, $55.26 \%$ of participants belonged to the joint family, $41.31 \%$ belonged to the nuclear family and $3.42 \%$ belonged to the three-generation family. $71.57 \%$ of participant used to do full-time farming and $28.42 \%$ participant used to do seasonal farming. Study done by Norkaewl Saowanee et al $^{9}$ on knowledge, attitude, and practice of using Personal Protective Equipment (PPE) for chilli growing farmers in Huarua sub-district, Mueang district, Ubon Ratchathani province, Thailand they found that $53 \%$ study participant were males and $47 \%$ were females. There were 3 $\%$ never educated, $71.2 \%$ primary school educated, $15.2 \%$ high school educated and $1.5 \%$ of the participants had a bachelor's degree.

In the present study, we found that the majority of the participants had knowledge of pesticide about $63.4 \%$ agricultural workers knew that pesticides were harmful, 58.15 $\%$ participant purchased pesticide from Krushi Kendra, 15.26 $\%$ participant from private shop and $26.57 \%$ participant purchased from co-farmers.

In a study conducted by Bhanti et al ${ }^{10}$ in rural block of Agra region found that $90 \%$ farmers thought that pesticides are harmful, the difference in knowledge could be due to difference in socioeconomic background and literacy levels amongst study participants. This study shows that $36.31 \%$ of participant used sticks to mix pesticide while $45 \%$ used bare hands for mixing (non-tabulated data). Almost $42.63 \%$ of study participants claimed to wash their hands with soap and $56.31 \%$ participant with plain water after using the pesticide.

It was observed that in regards to storage practices of pesticides the majority of participants 126 (33.15\%) stored pesticides in the storeroom, $57(15 \%)$ stored pesticides outside the house and 197 (51.84\%) stored pesticides inside the house. Washing practices of pesticide equipment was found that the majority of 187 (49.21\%) participants were washing equipment on the farm 165 (43.42\%) were washing equipment outside the home and 28 (7.365 \%) were washing equipment at home (non-tabulated data).

In a study conducted by MV Sai et al ${ }^{11}$ knowledge and perception of farmers regarding pesticide usage in a rural farming village southern India found that most farmers $(52.63$ $\%$ ) learned regarding pesticides by communicating with retailers while $25.73 \%$ knew about it by interacting with cofarmers and $21.64 \%$ used consultancies to make themselves aware. Almost all the farmers (93.57\%) claimed to wash their hands with soap after using pesticides. The difference in our study findings may be due to different socio economic and literacy levels.

In our study more than half of the study participants reported headache as major complaint followed by skin irritation in about $44.21 \%$ participants while only $4.73 \%$ and $2.89 \%$ study participants were suffering from shortness of breath and stomach ache respectively. In a study conducted by Sunil Mittal et al ${ }^{12}$ in Malwa region of Punjab concluded that there was a sharp increase in pesticide related cancers, reproductive disorders and mental retardation. The affected region and the most affected individuals were agricultural workers who were directly involved in pesticide handling.

We found significant association between literacy levels, socio economic status, gender and age groups and perception regarding harms caused by pesticides, this are similar to study done by Lekei EE et $\mathrm{al}^{13}$ in villages in Tanzania where they found that respondents with higher education levels were significantly less likely to store pesticides in their home (PRR High / Low $=0.3 ; 95 \% \mathrm{CI}=0.1-0.7$ ) and more likely to practice calibration of spray equipment (PRR high / low $=1.2$; $95 \% \mathrm{CI}=1.03-1.4$ ). However they found that knowledge of routes of exposure was not associated with safety practices particularly for disposal, equipment wash area, storage and use of personal protective equipment.

\section{CONCLUSIONS}

About two thirds of the study participants thought that pesticides are injurious to health \& environment. While only one fourth of the participants knew about of route of entry of pesticides into the body. A variety of toxic clinical symptoms associated with pesticide exposure including headaches, dizziness, skin irritation, nausea, itchy eyes, vomiting, coughing, shortness of breath, excessive sweating, fatigue, stomachache, and blurred vision were seen. Association between perception of harmful effects of pesticides and sociodemographic profile was found to be statistically significant indicating that socio-demographic profile had a crucial role in determining the perception regarding pesticides. 


\section{Limitations}

- This cross-sectional study was conducted in only 3 adopted villages thus study finding may not be generalized for other settings; hence, external validity of study findings is limited.

- Many variables determining the perception and practices related to the use of pesticide \& PPE are not sufficiently understood through quantitative studies and qualitative research is necessary to determine the behaviour pattern with regard to use of pesticides and PPE.

Data sharing statement provided by the authors is available with the full text of this article at jemds.com.

Financial or other competing interests: None.

Disclosure forms provided by the authors are available with the full text of this article at jemds.com.

\section{REFERENCES}

[1] Shetty PK, Murugan M, Hiremath MB, et al. Farmers' education and perception on pesticide use and crop economies in Indian agriculture. J Exp Sci 2010;1(1):3-8.

[2] India and Importance. Agriculture in India: industry overview, market size, role in development. India Brand Equity Foundation India Brand Equity Foundation Org 2018.

[3] World Health Organization. International programme on chemical safety, guidelines on the prevention of toxic exposures education and public awareness activities. Geneva: World Health Organization 2004.

[4] Pesticide Law and Definitions-Environmental Protection Agency: 2014. Federal Insecticide, Fungicide, and Rodenticide Act (FIFRA) www.epa.gov/compliance/resources/.../fifra/.../ fifra/fiframanch_02.pdf.

[5] DEQ Oregon. Guidance for evaluating residual Pesticides on lands formerly used for Agricultural production. January 2006.
[6] Report of the WPRO regional workshop on epidemiology of poisoning by pesticides held in Singapore. Dec, 1999.

[7] Fenske RA, Day EW. Assessment of exposure for pesticide handlers in agricultural, residential and institutional environments. In: Franklin CA, Worgan JP, Eds. Occupational and residential exposure assessment for pesticides. Chichester, UK: John Wiley \& Sons 2005:13-43.

[8] Miller SL. Personal protective equipment for agriculture, the university of wyoming college of agriculture and natural resources. Office of Communications and Technology Agust 2012.

[9] Norkaew S, Siriwong W, Siripattanakul S, et al. Knowledge, Attitude, and Practice (KAP) of Using Personal Protective Equipment (PPE) for Chih-Growing Farmers in Huarua Sub-District, Mueang District, Ubonrachathani Province, Thdand. Journal of Health Res 2010;24(Suppl 2):93-100.

[10] Bhanti M, Shukla G, Taneja A. Contamination levels of organochlorine pesticides and farmers' knowledge, perception, practices in rural india: a case study. Bulletin of Environmental Contamination and Toxicology 2004;73:787-93.

[11] Satya Sai MV, Revati GD, Ramya R, et al. Knowledge and perception of farmers regarding pesticide usage in a rural farming Village, Southern India. Indian J Occup Environ Med 2019;23(1):32-6.

[12] Mittal S, Kaur G, Vishwakarma GS. Effects of Environmental Pesticides on the Health of Rural Communities in the Malwa Region of Punjab, India: a review. Human and Ecological Risk Assessment: An International Journal 2014;20(2):366-87.

[13] Lekei EE, Ngowi AV, London L. Farmers' knowledge, practices and injuries associated with pesticide exposure in rural farming villages in Tanzania. BMC Public Health 2014;14:389. 